\title{
COMPARATIVE STUDY BETWEEN USAGE OF PLATELET-RICH PLASMA AND BOTULINUM TOXIN-A INJECTION IN MANAGEMENT OF MYOFASCIAL PAIN DYSFUNCTION. (A RANDOMIZED CLINICAL TRIAL)
}

\author{
Usama Abd El Raouf M. El Dakrory*
}

\begin{abstract}
Myofascial Pain Dysfunction (MPD) is a common musculoskeletal pain disorder with a female prevalence that may reach up to $60 \%$. The aim of this randomized clinical trial (RCT) is to compare the usage of Platelet-Rich Plasma (PRP) and Botulinum toxin-A (BTX-A) injection in management of MPD.

Patients and methods: The study included 27 female patients suffering from MPD related to masseter and temporalis muscles. They were selected from outpatient clinics of College of Oral and Dental Surgery, Misr University for Science and Technology (MUST) and Oral and Maxillofacial unit, Memorial Souad Kafafi University Hospital, MUST. Patients were randomly divided into two groups, "Group I" included 13 patients while "Group II" included 14 patients. Five trigger points were localized ( 3 in masseter and 2 in temporalis muscles). "Group I" was injected with $0.5 \mathrm{ml}$ of PRP in each TrP, while "Group II" was injected with 5 units of BTX-A in each TrP. Assessment based on: Visual Analogue Scale (VAS) for subjective pain, Maximal Interincisal Opening (MIO), and Pressure Pain Intensity (PPI). Assessment was performed preoperatively and at follow-up periods of 4,12 , and 24 weeks.
\end{abstract}

Results: At all follow-up periods, VAS scores for group I were significantly higher than group II. MIO results for group II were significantly higher than group I. Lastly, at all follow-up periods, PPI scores were significantly higher in group I than group II.

Conclusions: BTX-A injection results are superior to that of PRP injection and could be considered a better treatment for MPD.

* Lecturer, Oral and Maxillofacial Surgery, College of Oral and Dental Surgery, Misr University for Science \& Technology, Cairo, Egypt 


\section{INTRODUCTION}

Myofascial Pain Dysfunction (MPD) in head and neck region is associated with increased parafunctional habits such as bruxism, nail biting, grinding and teeth clenching leading to microtrauma to muscle, tension, fatigue, and spasm. ${ }^{[1]}$

Psychological element is important, ${ }^{[1-3]}$ according to Simons et $\mathrm{al}^{[4]}$ sleep disorder, sleep deprivation, stress, and anxiety are essential contributors in MPD, they are related to chronic pain, fatigue and impairment of descending inhibitory system. Hence, MPD is considered a psychosomatic disorder. ${ }^{[5]}$

MPD is characterized by the presence of myofascial trigger points (TrPs) which is a clinical hallmark. Trigger points are localized, deep, and tender taut bands within skeletal muscles and muscles of mastication. They are also discrete, hyperirritable, and painful on palpation. TrPs can reduce the range of mouth opening, able to produce referred pain, local twitch or contraction, and increased sympathetic output. ${ }^{[6-12]}$ Identification of trigger points (TrPs) is obtained by perpendicular palpation for short time ranging from 5-10 seconds, this commonly elicit an involuntary quick, nervous movement "flinching or jump sign" that is not proportionate to the amount of pressure applied, pain is felt in the same distribution as the patient's complaints. ${ }^{[13]}$

MPD exact prevalence is not certain. ${ }^{[3]}$ According to study conducted by Fricton JR et al ${ }^{[7]}$ myofascial pain was presented in $55 \%$ of the study cases, while Bennett ${ }^{[13]}$ reported that $95 \%$ of patients presented to pain management centers were found to be myofascial pain dysfunction. Generally MPD is more prevalent in female than male with prevalence percentage about $55-60 \%$ of population, ${ }^{[14,15]}$ at the age between $20-50$ years, this may be due to psychological background and hormonal changes in association with reduced pain tolerance. ${ }^{[3,15]}$ Others reported a female precedence by $65-84 \% .^{[16,17]}$
Different treatment modalities have been used to manage MPD including physical and Pharmacological modalities. Heat application is the most commonly used physical modality, ${ }^{[18]}$ it increases blood flow, wash away of pain mediators with reduction of muscle spasm leading to pain reduction. Ultrasound (US) application and Electrical therapy are another physical modalities, ${ }^{[19]}$ US provides deep heat with higher subcutaneous penetration on the contrary to hot pads that affect superficially. Contraindications of heat application are circulatory insufficiency, malignancy, and inflammation. While electrical therapy can improve vascular circulation to eliminate inflammatory byproducts from the painful site. ${ }^{[19]}$ Needling is a known technique used in treatment of MPD either when using local anaesthesia with $27 \mathrm{G}$ hypodermic needles or when using the less painful and finer acupuncture needles with no use of local anesthetics, the idea behind needling is to break fibrotic spots within the muscle leading to symptoms relief. ${ }^{[4,20]}$

Pharmacological treatment is another option that is used in management of MPD including muscle relaxants, and analgesics like paracetamol, nonsteroidal anti-inflammatory drugs (NSAIDs) or the recent Cox-2 inhibitor drugs. Adjuvant medications as antidepressants or anticonvulsants can add value in treatment when MPD has a neuropathic element, emotional stress, and sleep deprivation. ${ }^{[19,20]}$

One of the commonly used method in management of MPD is the use Platelet-Rich Plasma (PRP) with a history dated back to 1970 by Pihut et al and others ${ }^{[21-23]}$ who used it in management of temporomandibular disorders (TMD) and muscle related injuries and for more than 30 year, many authors ${ }^{[24-27]}$ have discussed its usage in management of musculoskeletal injuries as a minimally invasive treatment with very negligible allergy.

The core of PRP modality is to obtain a platelet concentration that can reach up to 8 times higher than the basic blood level leading to concentration 
of main growth factors. ${ }^{[28]}$ Many growth factors are derived from platelets as transforming growth factor (TGF- $\beta$ ), vascular endothelial growth factor (VEGF), nerve growth factor (NGF) and plateletderived growth factor (PDGF), these factors are of prime importance in enhancement of muscle regeneration and healing with reduction of chronic pain which is the core of management of MPD. ${ }^{[29,30]}$

Another treatment modality used in management of MPD is use of Botulinum toxin (BTX-A) injection, despite that, therapeutic usage of Botulinum toxin started by Scott et al in 1973, the first reported use in management of temporomandibular disorders was by Freund and Schwartz in 1998 to be continued in management of MPD effectively. ${ }^{[31,32]}$

Botulinum toxin-A (BTX-A) is a clinically applicable subtype among eight subtypes of exotoxin of the gram positive anaerobic Clostridium botulinum that temporarily inhibits the skeletal muscle through blocking calcium-mediated release of acetylcholine from motor nerve endings causing skeletal muscle paralysis or weakness. [33-35] It is worthy to mention that, BTX-A has no effect on sensory conduction as it only interacts with cholinergic receptors. ${ }^{[36,37]}$ Despite the rapid onset of the effect on the motor nerve ending yet, the duration of action lasts for three to five months which is the time needed for neural sprouting and reinnervation of the muscle. ${ }^{[33]}$

The aim of this is to compare the usage of Platelet-Rich Plasma (PRP) and Botulinum toxin-A (BTX-A) injection in management of MPD

\section{PATIENTS AND METHODS}

The study presented 27 female patients with age ranging from 20-40 years. Patients were selected, clinically examined, and treated at the outpatient clinics of College of Oral and Dental Surgery, MUST and the Oral and Maxillofacial unit, Memorial Souad Kafafi University Hospital, MUST. The study was conducted in the period from November 2018 till February 2020.
Patients complained from pain affecting jaw muscle and the side of head, pain exacerbates with talking and food chewing. On clinical examination, perpendicular palpation on master and temporalis muscles for 5 seconds was painful with localized, tender, and hyperirritable points; the trigger points (TrPs). Palpation of TrPs resulted in involuntary quick "jumping" pain. Temporomandibular joint (TMJ) was clinically examined and was found normal and asymptomatic, absence of TMJ disorders either bony degenerative changes or soft tissue changes was confirmed using panoramic radiograph and magnetic resonance imaging. Intraoral examination was performed to detect any dental cause of pain. After clinical examination diagnosis was confirmed as MPD. Three patients had bilateral symptoms, giving the study a total of 30 records to study.

Patients were selected according to inclusion criteria that include being females with age ranging from 20-40 years suffering from unilateral or bilateral signs and symptoms of MPD, selected patients were systemically free with no chronic diseases.

Exclusion criteria included: patients with TMJ disorders either due to bony degenerative changes or soft tissue changes. Patients with history of malignancy or a history of previous surgery of neck and/or shoulder within the past year of the study were excluded. Any patient had treatment that can affect the muscles was excluded, either pharmacological treatment (e.g., opioids, morphine, muscle relaxants or anti-depressants), physiotherapy management or occlusal appliances. Patients with pain of dental etiology were excluded, Pregnant and lactating women and patients with history of allergy or coagulation disorders were also excluded.

Patients were divided into two groups randomly using envelops selection, 27 identical unmarked sealed envelopes each contains a line of treatment under studying were presented to all patients to choose freely. 
"Group I" included 13 patients who will be treated with PRP injection, two patients in this group had bilateral symptoms, this made group I to be represented by 15 records to be studied. "Group II" included 14 patients who will be managed with BTX-A injection, one patient had bilateral symptom, making group II to be represented by 15 records for studying. Treatment procedures were explained to all patients regarding injection procedures, post operative medications if needed, assessment procedures both preoperatively and postoperative follow-up were also explained. Patients' approval was obtained.

Assessment was performed using three parameters including: Visual Analogue Scale score for subjective pain, Maximal Interincisal Opening, and Pressure Pain Intensity score. Preoperative assessment was performed for both groups and data were collected to compare and statistically analyze the initial data before treatment initiation. After injection, follow-up was performed using the three mentioned parameters at three periods, 4 weeks, 12 weeks, and 24 weeks postoperatively.

\section{Assessment based on:}

1- Subjective pain using Visual Analogue Scale (VAS) score from 0-10. The patient was asked to select a number from $0-10$ that represented the pain she feels, where 0 represents no pain and 10 represents the worst pain.

2- Maximal Interincisal Opening (MIO) in $\mathrm{mm}$, using a digital caliper.

3- Pressure Pain Intensity (PPI) score, a pain intensity scale from $0-3 .^{[38-40]}$ obtained by performing pressure on the trigger points in master and temporalis muscle through applying thumb pressure on skin for about 5 seconds then recording the PPI score as listed below.

0 No report of pain and no visible reaction.

1 Report of pain.

2 Painful tenderness and visible reaction on the face.

3 Severe pain and marked visible reaction or avoidance.

\section{Group I}

Patients in this group were treated using platelet rich plasma (PRP) injection.

\section{PRP preparation:}

PRP Preparation was performed using electric centrifuge machine (Electric Centrifuge model 80-1 / 4000 RPM / 6* 20 ml. Wincom Company Ltd. China), Fig. (1), $27 \mathrm{ml}$ of autologous blood was collected through venous puncture to be divided into 3 tubes; each tube contains $1 \mathrm{ml} \mathrm{3.8 \%} \mathrm{sodium}$ citrated to which $9 \mathrm{ml}$ of the collected venous blood will be added. Another 3 tubes filled with $10 \mathrm{ml}$ of saline were inserted in the remaining 3 spots in the centrifuge in alternating pattern to provide balance and stability during spinning. According to Anitua E. et al ${ }^{[41]}$ tubes were centrifuged at $1800 \mathrm{rpm}$ for 15 min "soft spin", leading to separation of plasma (top layer) from packed red blood cells (RBCs).

Plasma layer was transferred to another sterile tube without anticoagulant and RBCs layer was discarded. Second centrifuging at $3500 \mathrm{rpm}$ for 10 min "hard spin" was performed separating the platelet poor plasma "PPP" layer on the uppermost $2 / 3$ that would be discarded leaving the platelet rich plasma "PRP" layer at the $1 / 3$ bottom which is the layer of interest. ${ }^{[42-44]}$ Collectively, 2.5-3 $\mathrm{ml}$ of PRP was obtained. Fig. (2)

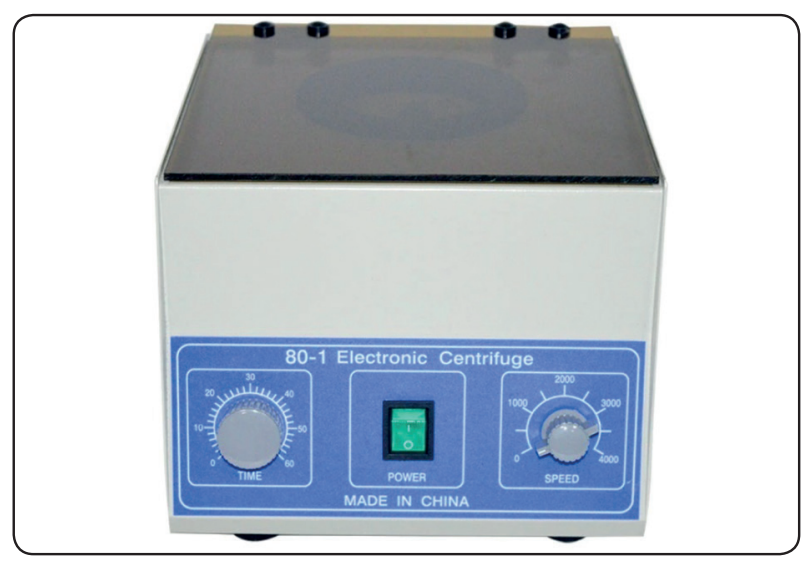

Fig. (1): Centrifuge model 80-1, (China) 


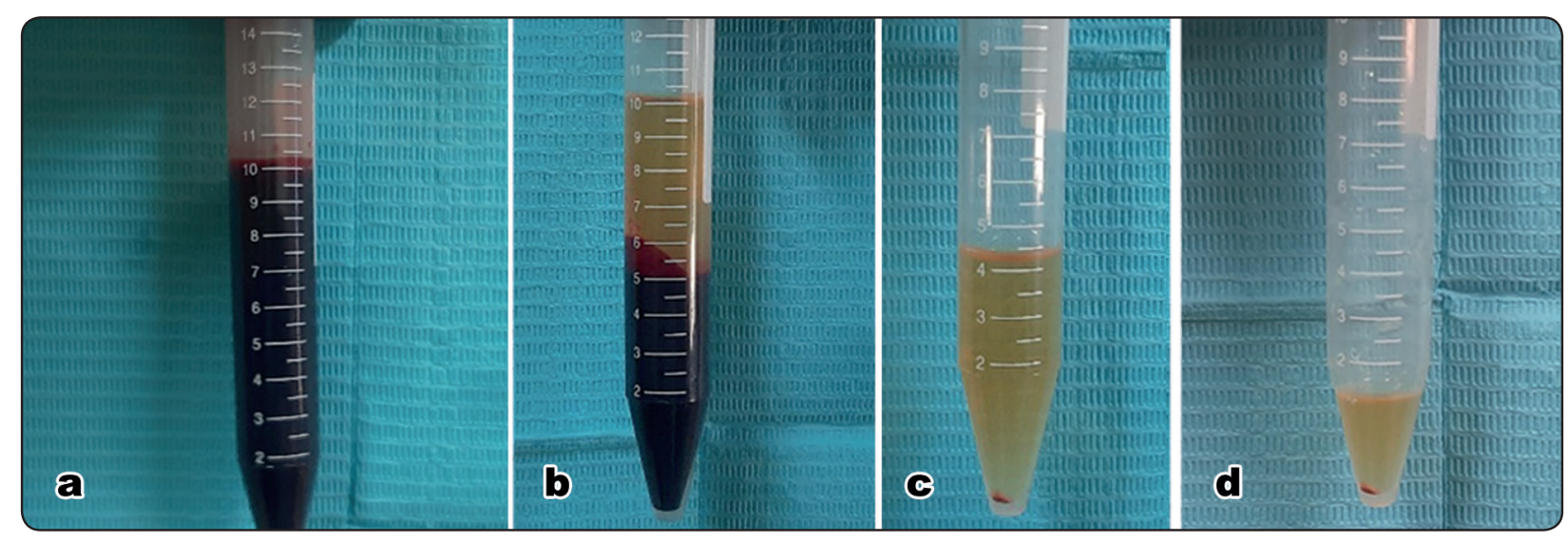

Fig. (2): Shows the steps of PRP preparation (a-d)

Palpation of masseter and temporalis muscles were performed in a perpendicular way for 5 seconds to localize the TrPs. Three trigger points in masseter and two in temporalis muscles were localized and overlying skin were marked Fig. (3).

After using of Alcohol Pre-Injection Swab 70\% for skin cleansing, injection of $0.5 \mathrm{ml}$ per each trigger point was performed (5 TrPs x $0.5 \mathrm{ml}$ ) Fig. (4). All patients were advised to avoid excessive use of masticatory muscles for 7 days and to adhere to soft diet with avoidance of gum chewing. In addition, paracetamol was the recommended analgesic when needed, as non-steroidal anti-inflammatory drugs (NSAIDs) can significantly impair platelet aggregation and in turn the efficiency of PRP healing effect. ${ }^{[27,45]}$

\section{Group II}

Patients in this group were treated using Botulinum toxin-A (BTX-A) injection. The used subtype was "Botulinum toxin type A" which is "Botox Allergan ${ }^{\circledR ”} 100$ units by Westport Co. Mayo, Ireland. According to manufacturer instructions, every 50 units is reconstituted with $1 \mathrm{ml}$ saline to obtain a concentration of 5 units $/ 0.1 \mathrm{ml}$.

As with group I, trigger points were identified and marked, three trigger points in masseter muscle and two points in temporalis muscle, these points were

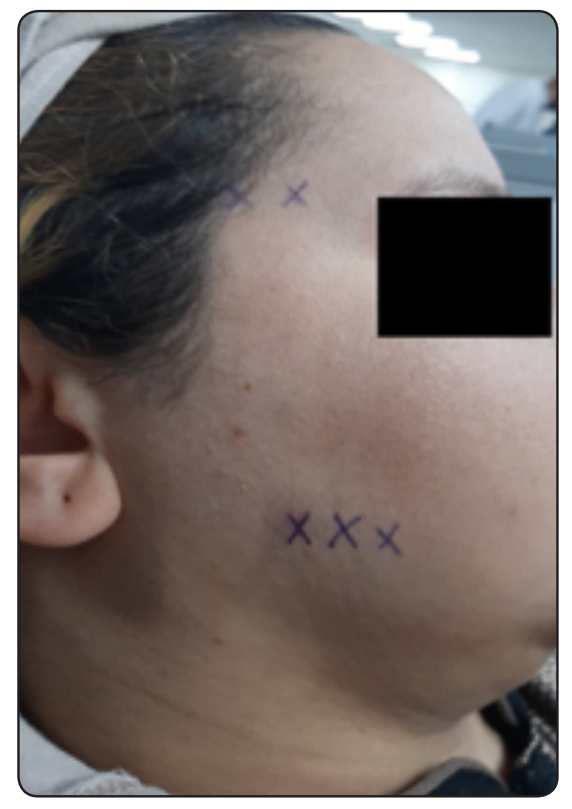

Fig. (3): Marked TrPs

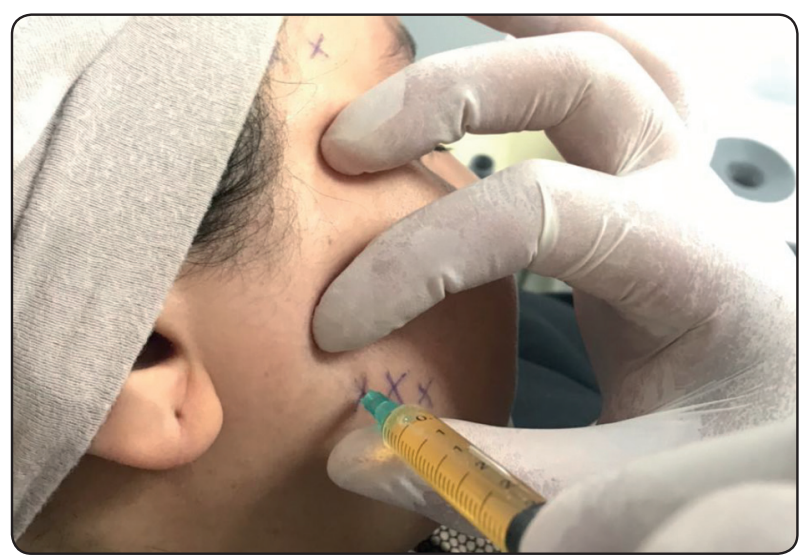

Fig. (4): PRP injection 
selected cautiously to avoid facial nerve affection. In order to maintain good concentration of BTX-A at the selected injections points, patients were asked to apply ice pack on the muscle 5 minutes before injection to reduce blood supply to injection area.

After using of Alcohol Pre-Injection Swab 70\% for skin cleansing, 5 units $(0.1 \mathrm{ml})$ were injected in each trigger point after negative aspiration, (5 TrPs x $0.1 \mathrm{ml}$ ). Ice packs were applied immediately after injection to reduce the post-operative pain.

Follow-up was performed at the outpatient clinics in College of Oral and Dental Surgery, MUST and the Oral and Maxillofacial unit, Memorial Souad Kafafi University Hospital, MUST. Follow-up based on three parameters including: Visual Analogue Scale (VAS) scores for subjective pain assessment, Maximal Interincisal Opening, and Pressure Pain Intensity scores, it was performed at three periods of follow-up, 4 weeks, 12 weeks, and 24 weeks postoperatively.

\section{Statistical analysis:}

Numerical data was represented as mean and standard deviation (SD) values. Shapiro-Wilk's test was used to test for normality. Homogeneity of variances was tested using Levene's test. Maximal interincisal opening values showed parametric distribution and variance homogeneity, so they were analyzed using independent t-test for intergroup comparisons and one-way repeated measures ANOVA followed by Bonferroni post hoc test for intragroup comparisons. Other data showed nonparametric distribution, so they were analyzed using Mann-Whitney U test for intergroup comparisons and Freidman's test followed by Dunn's post hoc test for intragroup comparisons. The significance level was set at $\mathrm{p}<0.05$ within all tests. Statistical analysis was performed with $\mathrm{R}$ statistical analysis software version 4.1.0 for Windows* .

\section{RESULTS}

Results of intergroup and intragroup comparisons for VAS were presented in table (1). At baseline, the difference between the two groups was not significant $(\mathrm{P}=0.219)$ while at all other follow-up intervals PRP group had a significantly higher value than BTX group $(\mathrm{p}<0.001)$. For both groups, there was a significant difference between values recorded at different follow-up periods $(\mathrm{p}<0.001)$. Average values for VAS were presented in Fig. (5).

TABLE (1): Inter and intragroup comparisons for VAS

\begin{tabular}{cccc}
\hline \multirow{2}{*}{ Time } & \multicolumn{2}{c}{ VAS $($ Mean \pm SD) } & p-value \\
\cline { 2 - 3 } & PRP & BTX & \\
\hline Pre-operative & $8.00 \pm 0.76^{\mathrm{a}}$ & $8.33 \pm 0.72^{\mathrm{a}}$ & 0.219 \\
\hline 4 weeks & $4.93 \pm 0.80^{\mathrm{c}}$ & $2.27 \pm 1.22^{\mathrm{b}}$ & $<0.001^{*}$ \\
\hline 12 weeks & $4.87 \pm 0.92^{\mathrm{c}}$ & $2.27 \pm 0.96^{\mathrm{b}}$ & $<0.001^{*}$ \\
\hline 24 weeks & $6.27 \pm 1.49^{\mathrm{b}}$ & $2.87 \pm 0.83^{\mathrm{b}}$ & $<0.001^{*}$ \\
\hline
\end{tabular}

Different superscript letters indicate a statistically significant difference within the same vertical column; *significant $(p<0.05)$

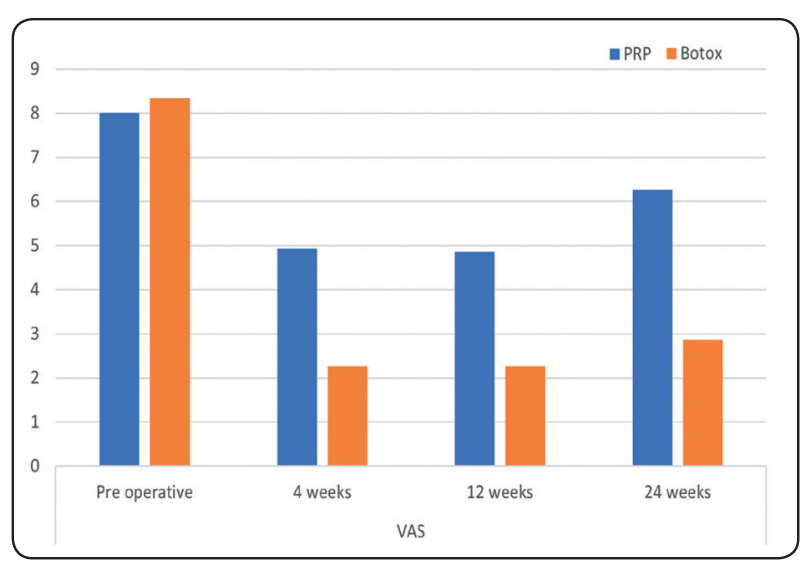

Fig. (5): Bar chart showing average VAS.

* R Core Team (2021). R: A language and environment for statistical computing. R Foundation for Statistical Computing, Vienna, Austria. URL https://www.R-project.org/. 
Results of intergroup and intragroup comparisons for maximal interincisal opening (MIO) presented in table (2) showed BTX group to have a significantly higher MIO readings than PRP group after 4 weeks $(\mathrm{p}=0.006)$ and after 24 weeks $(\mathrm{p}<0.001)$, while for other intervals there was no significant difference between both groups ( $>>0.05)$. For both groups, there was a significant difference between values recorded at different intervals $(\mathrm{p}<0.001)$, with the highest value recorded after 12 weeks and the lowest value found pre-operatively. Average values for mouth opening were presented in Fig. (6).

TABLE (2): Inter and intragroup comparisons for Maximal Interincisal Opening (MIO) $(\mathrm{mm})$

\begin{tabular}{cccc}
\hline \multirow{2}{*}{ Time } & \multicolumn{2}{c}{ MIO $(\mathrm{mm})($ Mean \pm SD $)$} & \\
\cline { 2 - 3 } & PRP & BTX & \\
\hline Pre-operative & $32.53 \pm 2.45^{\mathrm{c}}$ & $32.36 \pm 1.53^{\mathrm{c}}$ & 0.547 \\
\hline 4 weeks & $36.68 \pm 2.82^{\mathrm{b}}$ & $39.30 \pm 1.02^{\mathrm{b}}$ & $0.006^{*}$ \\
\hline 12 weeks & $39.06 \pm 2.90^{\mathrm{a}}$ & $40.36 \pm 0.74^{\mathrm{a}}$ & 0.547 \\
\hline 24 weeks & $33.66 \pm 3.15^{\mathrm{c}}$ & $39.67 \pm 1.01^{\mathrm{b}}$ & $<0.001^{*}$ \\
\hline
\end{tabular}

Different superscript letters indicate a statistically significant difference within the same vertical column; *significant $(p<0.05)$

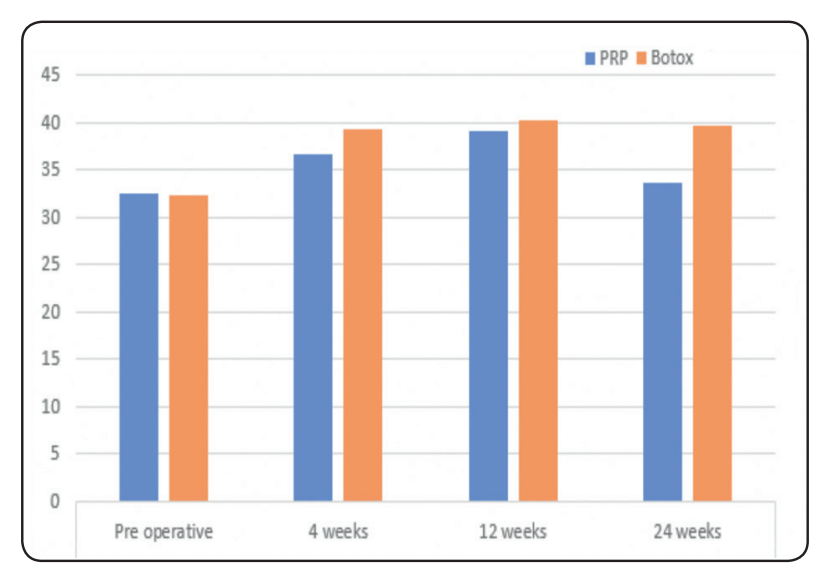

Fig. (6): Bar chart showing average Maximal Interincisal Opening (MIO) (mm).
Results of intergroup and intragroup comparisons for PPI score masseter and temporalis were presented in tables (3) and (4) respectively. At baseline, the difference between the two groups was not significant $(\mathrm{P}>0.05)$ while at all other follow-up intervals PRP group had a significantly higher value than BTX group $(p<0.001)$. For both groups, there was a significant difference between values recorded at different follow-up intervals $(\mathrm{p}<0.001)$. Average values for masseter and temporalis PPI score were presented in Fig. (7) and (8) respectively.

TABLE (3): Inter and intragroup comparisons for Pressure Pain Intensity (PPI) for masseter muscle.

\begin{tabular}{cccc}
\hline \multirow{2}{*}{ Time } & \multicolumn{2}{c}{ Masseter PPI (Mean \pm SD) } & \\
\cline { 2 - 3 } & PRP & BTX & \\
\hline Pre-operative & $2.53 \pm 0.52^{\mathrm{a}}$ & $2.60 \pm 0.51^{\mathrm{a}}$ & 0.717 \\
\hline 4 weeks & $1.47 \pm 0.52^{\mathrm{b}}$ & $0.27 \pm 0.59^{\mathrm{b}}$ & $<0.001^{*}$ \\
\hline 12 weeks & $1.40 \pm 0.51^{\mathrm{b}}$ & $0.40 \pm 0.83^{\mathrm{b}}$ & $<0.001^{*}$ \\
\hline 24 weeks & $1.87 \pm 0.35^{\mathrm{b}}$ & $0.73 \pm 0.80^{\mathrm{b}}$ & $<0.001^{*}$ \\
\hline
\end{tabular}

Different superscript letters indicate a statistically significant difference within the same vertical column; *significant $(p<0.05)$

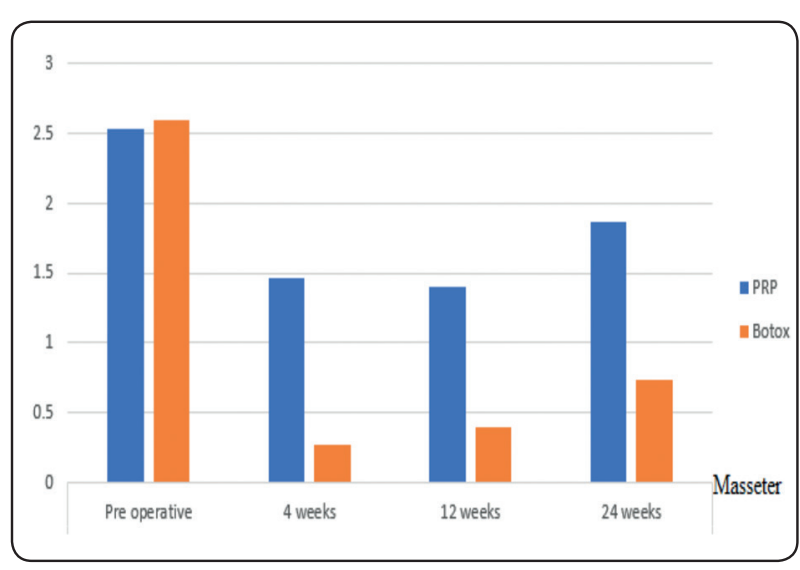

Fig (7): Bar chart showing average Pressure Pain Intensity (PPI) for masseter muscle. 
TABLE (4): Inter and intragroup comparisons for Pressure Pain Intensity (PPI) for temporalis muscle.

\begin{tabular}{cccc}
\hline \multirow{2}{*}{ Time } & \multicolumn{2}{c}{ Temporalis PPI $($ Mean \pm SD $)$} & \\
\cline { 2 - 3 } & PRP & BTX & \\
\hline Pre-operative & $2.47 \pm 0.52^{\mathrm{a}}$ & $2.53 \pm 0.52^{\mathrm{a}}$ & 0.720 \\
\hline 4 weeks & $1.20 \pm 0.56^{\mathrm{c}}$ & $0.27 \pm 0.80^{\mathrm{c}}$ & $<0.001^{*}$ \\
\hline 12 weeks & $1.40 \pm 0.51^{\mathrm{bc}}$ & $0.40 \pm 0.83^{\mathrm{bc}}$ & $<0.001^{*}$ \\
\hline 24 weeks & $1.87 \pm 0.35^{\mathrm{b}}$ & $0.80 \pm 0.77^{\mathrm{b}}$ & $<0.001^{*}$ \\
\hline
\end{tabular}

Different superscript letters indicate a statistically significant difference within the same vertical column; *significant $(p<0.05)$.

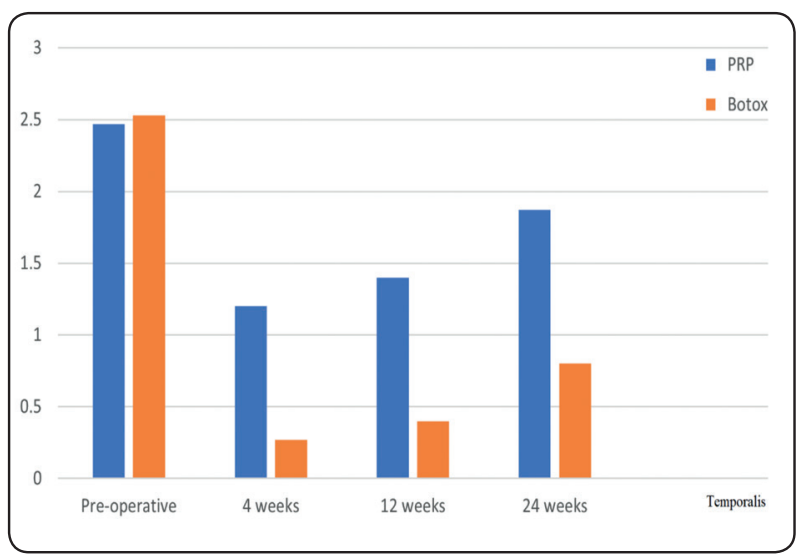

Fig. (8): Bar chart showing average Pressure Pain Intensity (PPI) for temporalis muscle.

\section{DISCUSSION}

Myofascial pain Dysfunction is a widely prevalent disorder worldwide, it is not surprising that few people go through life without experiencing episodes of MPD, it is associated with the presence of myofascial trigger points which are hyperirritable foci in the muscle. ${ }^{[8]}$

This study compares the use of two different methods for management of MPD, namely PRP injection and BTX injection.
Many preparation protocols have been used to prepare PRP. ${ }^{[46]}$ For practically, PRP preparation protocols can summarized into two techniques, single-spinning and double-spinning techniques.

The single-spinning approach is able to provide a concentrate of platelets up to 3 times of the baseline level, while double-spinning technique provides 4to 8-folds of the original baseline level of platelets. ${ }^{[47]}$ Some authors ${ }^{[48-50]}$ consider that single spinning technique provides an enhanced and accelerated effect where platelets concentration is reasonably above the base level and in the same time, with minimal alterations in platelet morphology.

In this study, Double spinning technique was used, it provides maximal platelet concentrate that reaches 8 folds of the basic level with minimal amount of leucocytes and as showed by many studies, ${ }^{[51-53]}$ PRP rich in leucocytes is associated with increase in Interleukin-6 (IL-6) which is linked to chronic pain. On the other hand, Mei-Dan et al, ${ }^{[54]}$ see that, double spinning comes with a shortage which is the premature platelet degranulation, consequently, reduction in growth factors which are the main target. Anyhow, Filardo et al ${ }^{[47]}$ could not find significant statistical difference between single and double spinning technique.

BTX-A inhibits $\alpha$ motor neurons and $\gamma$ efferents leading to reduction in contractile force and reduction in muscle tone leading to muscle weakening. ${ }^{[55]}$ In turn, pain is reduced in an indirect way, BTX-A has no direct analgesic effect or sensory nerves effect. ${ }^{[56]}$

In this study, results of PRP group (Group I) showed that, VAS score was reduced to about score 5 during the first 4 weeks and continued at the 12 weeks postoperative follow-up period, this improvement declined to nearly score 6 at the 24 weeks follow-up period.

In a comparative study by Ediz et al, ${ }^{[57]}$ PRP injection has reduced VAS significantly at the end of 8 weeks of follow-up when compared with the 
baseline values. But on the contrary to our study, he did not find statistical difference at the first 4 weeks follow-up period. Sakalys et al, ${ }^{[28]}$ reported that, at 4 weeks postoperative follow-up period, he achieved $80 \%$ reduction in the VAS score recoded preoperatively. In comparison with our study, we achieved less than $40 \%$ reduction in our VAS scores results at 4 weeks postoperative period of follow-up.

Nitecka-Buchta ${ }^{[26]}$ recorded a $58 \%$ reduction in VAS score in his pilot study, VAS score has dropped from 5 preoperatively to about 2, within 5 days post injection and maintained improvement only for 14 days post injection. This is a very short time of improvement when compared to our study that showed improvement along 3 months. Generally, The short improvement period could be due to shortage in PRP preparation, technique of administration or localization of trigger points. ${ }^{[26]}$

On discussing results of BTX-A group (Group II), we obtained a marked reduction of VAS score that falls to $2-3$, this is nearly $75-80 \%$ reduction of the initial recorded score. This improvement occurred along the whole period of follow-up, taking into consideration the minor increase in VAS score at the period of 24 weeks. This coincides with many studies ${ }^{[56,58-62]}$ that reported improvement in VAS score. These studies reported that VAS score dropped to nearly 3 at the first 4 weeks and 12 weeks of postoperative follow-up period to end with accepted results to the period of 24 weeks postoperatively.

The second parameter of assessment is the maximal interincisal opening (MIO). In group I, gradual improvement occurred above the initial pre-injection level along the whole 12 weeks postoperatively (i.e., first and second postoperative follow-up periods) to show minor declination at the 24 weeks follow up period. We can claim that improvement obtained with PRP injection is due to the reduction of muscle pain associated with muscle regeneration and healing. Our results coincide with the results obtained from a study conducted by Postgraduate Institute of Dental Sciences Rohtak ${ }^{[63]}$ that found improvement of MIO during the first three months follow-up periods. On the contrary, others ${ }^{[64,65]}$ reported improvement in MIO records only for 4 weeks of follow-up.

Results of MIO in group II showed more improvement in comparison with that in group I, moreover improvement was almost maintained till the last period of follow-up, this coincides with other authors results. ${ }^{[35,59,66,67]}$ We can attribute this enhancement to inhibition of neural conduction of motor neurons with reduction in muscle contraction and subsequently relief of pain or even a change in pain threshold ${ }^{[36]}$, these lead to increase of range of motion, this agrees with explanation mentioned by other authors. ${ }^{[32,33,35]}$

Previous studies ${ }^{[33,37]}$ reported that, nerve regeneration and fading of BTX-A effect start from the third to fifth months after injection, this can explain the minor recession in our results at the period of 24 weeks postoperative followup. Accurate localization of trigger points is an important issue as demonstrated by Dutton et $\mathrm{al}^{[37]}$, who stated that injection of BTX at a point that is $0.5 \mathrm{~cm}$ away is associated with $50 \%$ reduction in the efficiency of the injection.

The last assessment parameter is the PPI score for both masseter and temporalis muscles using the PPI score. PRP injection was associated with reasonable reduction in PPI score of both muscles during the first and second postoperative follow-up periods (4 weeks and 12 weeks). The achieved improvement declined again at the 24 weeks of follow-up periods, yet not reach the initial level.

Matching results were seen with different studies ${ }^{[40,42,57]}$ showing that, the peak of improvement is obtained at 12 weeks postoperatively to decline again with increased pain intensity at the 24 weeks of the follow-up period. 
Regarding group II, we can attribute the obvious improvement in the PPI score to the effect of BTX-A injection that leads to reduction in muscle activity during both 4 weeks and 12 weeks followup periods. The increase in PPI score detected at the 24 weeks is due to nerve regeneration and fading of BTX effect. ${ }^{[33]}$ Our results is correlated with results of many authors ${ }^{[36,40,56]}$. Aa approximated results were obtained by of Bentsianov ${ }^{[68]}$ and others ${ }^{[32,36]}$ who found that pain intensity improved for 8 weeks follow-up, yet our results maintained improvement for 12 weeks.

This study aimed to compare between PlateletsRich plasma (PRP) and BTX-A injection in management of MPD, according to this study results, BTX-A injection is superior to PRP injection and results show significant difference in favor of BTX-A injection regarding the three parameters used in the study.

Studies conducting a comparison between these two modalities of treatment are few, anyhow, this study results are matching with results obtained from a study conducted by Yilmaz $\cdot{ }^{[40]}$ who reported that BTX-A injection has better results on comparison to of PRP injection regarding management of MPD. On contrary to our results, a meta-analysis study conducted by Al-Moraissi ${ }^{[69]}$ found that, pain reduction achieved for a short-term follow-up (up to three weeks) was maximum with PRP injection and not with BTX-A injection. Moreover, another metaanalysis studies ${ }^{[70,71]}$ concluded that PRP injection has a contradictory outcomes.

Limitation: Due to the nature of the study regarding using of PRP with the need to collect venous blood from the patient, blinding of the patient and the evaluator was not achieved.

\section{CONCLUSIONS}

MPD is a common musculoskeletal disorder that has been treated with different modalities. PRP and BTX injections were used in management of this dysfunction. Results of subjective pain visual analogue scale (VAS), maximal interincisal opening (MIO) and pressure pain intensity (PPI) for masseter and temporalis muscles were collected at 4,12 and 24 weeks of follow-up and compared to each other. It can be concluded that BTX injection is superior to PRP injection and could be considered a better treatment for MPD.

\section{REFERENCES}

1. Motghare, V., Kumar, J., Kamate, S., Kushwaha, S., Anand, R., Gupta, N., Gupta, B., Singh, I., Association Between Harmful Oral Habits and Sign and Symptoms of Temporomandibular Joint Disorders Among Adolescents. J Clin Diagn Res, 2015. 9(8): p. ZC45-ZC48.

2. Khalighi, H.R., Mortazavi, H., Mojahedi, S.M., Marhabi , S.A., Abbasabadi, F.M., Low Level Laser Therapy Versus Pharmacotherapy in Improving Myofascial Pain Disorder Syndrome. J Lasers Med Sci, 2016. 7(1): p. 45-50.

3. Ashour, E.M., Khalifa, F.A., Khalifa, G.A., Low Level Laser Therapy Versus Pharmacotherapy and Inter Occlusal Splint Therapy in Improving Myofascial Pain Disorder Syndrome. Al-Azhar Dental Journal for Girls, 2021. 8 (issue 1 January- Oral Medicine and Surgical Sciences issue (Oral Medicine, Oral and Maxillofacial Surgery, Oral Pathology, Oral Biology)): p. 91-97.

4. Simons, D.G., Travell, J.G., Simons, L.S., Myofascial Pain and Dysfunction: The Trigger Point Manual, 2nd Edition. (2 Volumes). Vol. 1. 1998, Baltimore: Williams \& Wilkins.

5. Panta, P., The Possible Role of Meditation in Myofascial Pain Syndrome: A New Hypothesis. Indian J Palliat Care, 2017. 23(2): p. 180-187.

6. Fouda, A., Comparison between four treatment modalities for active myofascial triggers points. Plast Aesthet Res 2014;1, P. 21-28.

7. Fricton, J.R., Kroening, R., Haley, D., Siegert, R., Myofascial pain syndrome of the head and neck: a review of clinical characteristics of 164 patients. Oral Surg Oral Med Oral Pathol, 1985.60(6): p. 615-23.

8. Abdel Aziz, O.M., Abdelmoneim, H.S., Myofascial pain treatment; local anesthesia injection versus corticosteroids. (ramdomized controlled clinical trial). Egyptian Dental Journal, 2019. 65 (Issue 4 - October (Oral Surgery), p. 3349-3355 
9. Wheeler, A.H., Myofascial pain disorders: theory to therapy. Drugs, 2004. 64(1): p. 45-62.

10. Hong, C.Z., Simons, D.G., Pathophysiologic and electrophysiologic mechanisms of myofascial trigger points. Arch Phys Med Rehabil, 1998 Jul;79(7):863-72.

11. Kuan, T.S., Hong, C.Z., Chen , J.T., Chen, S.M., Chien, C.H., The spinal cord connections of the myofascial trigger spots. Eur J Pain, 2007. 11(6): p. 624-34.

12. Gerwin, R.D., Myofascial Trigger Point Pain Syndromes. Semin Neurol, 2016. 36(5): p. 469-473.

13. Bennett, R., Myofascial pain syndromes and their evaluation. Best Pract Res Clin Rheumatol. 2007 Jun; 21(3), p.427-45.

14. LeResche, L., Epidemiology of temporomandibular disorders: implications for the investigation of etiologic factors. Crit Rev Oral Biol Med, 1997. 8(3): p. 291-305.

15. Vazquez-Delgado, E., Cascos-Romero, J., Gay-Escoda, C., Myofascial pain syndrome associated with trigger points: a literature review. (I): Epidemiology, clinical treatment and etiopathogeny. Med Oral Patol Oral Cir Bucal. 2009 Oct 1;14(10):e494-8

16. Healy, G.M., Finn, D.P., O'Gorman, D., Maharaj, C.H., Pretreatment anxiety and pain acceptance are associated with response to trigger point injection therapy for chronic myofascial pain. Pain Med, 2015. 16(10): p. 1955-66.

17. Butler, J.H., Folke, L.E., Bandt, C.L., A descriptive survey of signs and symptoms associated with the myofascial pain-dysfunction syndrome. J Am Dent Assoc, 1975. 90(3): p. 635-9.

18. Lynch, M.A., Brightman, V.J., Greenberg, M.S., Burket's Oral Medicine 9th edition. 9th edition ed. 1994: Lippincott-Raven.

19. Yap, E.C., Myofascial pain-an overview. Ann Acad Med Singap, 2007. 36(1): p. 43-8.

20. Borg-Stein, J. Iaccarino, M.A., Myofascial Pain Syndrome Treatments. Phys Med Rehabil Clin N Am, 2014 May; 25(2), p. 357-74.

21. Pihut, M., Szuta, M., Ferendiuk, E., Zeńczak-Więckiewicz, D., Evaluation of pain regression in patients with temporomandibular dysfunction treated by intra-articular plateletrich plasma injections: a preliminary report. Biomed Res Int, 2014, p. 132369.
22. Lin, S.L., Tsai, C.C., Wu, S.L., Ko, S.Y., Chiang, W.F., Yang,J.W., Effect of arthrocentesis plus platelet-rich plasma and platelet-rich plasma alone in the treatment of temporomandibular joint osteoarthritis: A retrospective matched cohort study (A STROBE-compliant article). Medicine (Baltimore), 2018. 97(16): p. e0477.

23. Reurink, G., Goudswaard, G.J., Moen, M.H., Weir, A., Verhaar, J.A., Bierma-Zeinstra, S.M., Maas, M., Tol, J.L., Platelet-rich plasma injections in acute muscle injury. $\mathrm{N}$ Engl J Med, 2014. 370(26): p. 2546-7.

24. Borrione, P., Gianfrancesco, A.D., Pereira, M.T., Pigozzi, F. Platelet-rich plasma in muscle healing. Am J Phys Med Rehabil. 2010 Oct;89(10):854-61.

25. Metcalf, K.B., Mandelbaum, B.R., McIlwraith, C.W., Application of Platelet-Rich Plasma to Disorders of the Knee Joint. Cartilage, 2013. 4(4): p. 295-312.

26. Nitecka-Buchta, A., Walczynska-Dragon, K., Kempa, W.M., Baron, S., Platelet-Rich Plasma Intramuscular Injections - Antinociceptive Therapy in Myofascial Pain Within Masseter Muscles in Temporomandibular Disorders Patients: A Pilot Study. Front Neurol. 2019 Mar 19;10:250.

27. Sampson, S., Gerhardt, M., Mandelbaum, B., Platelet rich plasma injection grafts for musculoskeletal injuries: a review. Curr Rev Musculoskelet Med, 2008. 1(3-4): p. 165-74.

28. Sakalys, D., Rokicki, JP., Januzis, G., Kubilius, R., Plasma rich in growth factors injection effectiveness for myofascial pain treatment in masticatory muscles. Randomised controlled trial. J Oral Rehabil. 2020 Jul;47(7):796-801.

29. Menetrey, J., Kasemkijwattana, C., Day, C.S., Bosch, P., Vogt, M., Fu, F.H., Moreland, M.S., Huard, J., Growth factors improve muscle healing in vivo. J Bone Joint Surg Br. 2000 Jan;82(1):131-7.

30. Pal, U.S., Mohammad, S., Singh, R.K., Das, S., Singh, S., Singh, M., Platelet-rich growth factor in oral and maxillofacial surgery. Natl J Maxillofac Surg, 2012. 3(2): p. 118-23.

31. Laskin, D.M., The Use of Botulinum Toxin for the Treatment of Myofascial Pain in the Masticatory Muscles. Oral Maxillofac Surg Clin North Am. 2018 Aug; 30(3), p. 287-289.

32. Freund, B., Schwartz, M., Symington, J.M.. The use of botulinum toxin for the treatment of temporomandibular disorders: preliminary findings. J Oral Maxillofac Surg. 1999 Aug; 57(8):916-20; discussion 920-1. 
33. Sipahi Calis, A., Colakoglu, Z., Gunbay, S., The use of botulinum toxin-a in the treatment of muscular temporomandibular joint disorders. J Stomatol Oral Maxillofac Surg. 2019 Sep;120(4), p. 322-325.

34. Chaurand, J., Pacheco-Ruíz, L., Orozco-Saldívar, H., López-Valdés, J., Efficacy of botulinum toxin therapy in treatment of myofascial pain. J Oral Sci. 2017;59(3), p. 351-356.

35. Freund, B., Schwartz, M., Symington, J.M., Botulinum toxin: new treatment for temporomandibular disorders. $\mathrm{Br}$ J Oral Maxillofac Surg, 2000. 38(5): p. 466-71.

36. Cheshire, W.P., Abashian, S.W., Mann, D.J., Botulinum toxin in the treatment of myofascial pain syndrome. Pain. 1994 Oct;59(1), p. 65-69..

37. Dutton, J.J., Botulinum-A toxin in the treatment of craniocervical muscle spasms: Short- and long-term, local and systemic effects. Surv Ophthalmol. 1996 Jul-Aug;41(1), p. 51-65.

38. Okeson, J., Management of Temporomandibular Disorders and Occlusion. 8th Edition ed. 2019: Mosby.

39. Ga, H., Choi, J.H., Park, C.H., Yoon, H.J., Acupuncture needling versus lidocaine injection of trigger points in myofascial pain syndrome in elderly patients - a randomised trial. Acupunct Med. 2007 Dec;25(4), p. 130-6..

40. Yilmaz, O., Sivrikaya, E.C., Taskesen, F., Pirpir, C., Ciftci, S., Comparison of the Efficacy of Botulinum Toxin, Local Anesthesia, and Platelet-Rich Plasma Injections in Patients With Myofascial Trigger Points in the Masseter Muscle. J Oral Maxillofac Surg. 2021 Jan;79(1):88.e1-88.e9.

41. Anitua, E., Prado, R., Sánchez, M., Orive, G., PlateletRich Plasma: Preparation and Formulation. Operative Techniques in Orthopaedics, 2012. 22(1): p. 25-32.

42. Morad, A., Abdellatif, E.M., Elmohandes, W.A., Evaluation of the role of platelet rich plasma injection in trigger point for treatment of myofacial pain. Al-Azhar Journal of Dental Science, 2018. 21(4): p. 347-355.

43. Filardo, G., Kon, E., Buda, R., Timoncini, A., Di Martino, A., Cenacchi, A., Fornasari, P.M., Giannini, S., Marcacci, M., Platelet-rich plasma intra-articular knee injections for the treatment of degenerative cartilage lesions and osteoarthritis. Knee Surg Sports Traumatol Arthrosc. 2011 Apr;19(4), p. 528-35.

44. Nugraha, H.K., Muljanti, M., Nugraha, K., Hernaningsih, Y., PLATELET RICH PLASMA PREPARATION PROTOCOLS: A PRELIMINARY STUDY. IJTID, 2012. 3: p. 104.
45. Schippinger, G., Prüller, F., Divjak, M., Mahla, E., Fankhauser, F., Rackemann, S., Raggam, R.B., Autologous Platelet-Rich Plasma Preparations: Influence of Nonsteroidal Anti-inflammatory Drugs on Platelet Function. Orthop J Sports Med. 2015 Jun 23;3(6):2325967115588896.

46. Dhurat, R., Sukesh, M., Principles and Methods of Preparation of Platelet-Rich Plasma: A Review and Author's Perspective. J Cutan Aesthet Surg. 2014 Oct-Dec;7(4):189-97.

47. Filardo, G., Kon, E., Pereira Ruiz, M.T., Vaccaro, F., Guitaldi, R., Di Martino, A., Cenacchi, A., Fornasari, P.M., Marcacci, M., Platelet-rich plasma intra-articular injections for cartilage degeneration and osteoarthritis: singleversus double-spinning approach. Knee Surg Sports Traumatol Arthrosc. 2012 Oct;20(10), p. 2082-91.

48. Eby, B.W., Platelet-rich plasma: harvesting with a singlespin centrifuge. J Oral Implantol. 2002;28(6), p. 297-301.

49. Wang-Saegusa, A., Cugat, R., Ares, O., Seijas, R., Cuscó, X., Garcia-Balletbó, M., Infiltration of plasma rich in growth factors for osteoarthritis of the knee short-term effects on function and quality of life. Arch Orthop Trauma Surg. 2011 Mar;131(3), p. 311-7.

50. Sampson, S., Reed, M., Silvers, H., Meng, M., Mandelbaum, B., Injection of platelet-rich plasma in patients with primary and secondary knee osteoarthritis: a pilot study. Am J Phys Med Rehabil. 2010 Dec;89(12), p. 961-9.

51. Zhou, YQ., Liu, Z., Liu, Z.H., Chen, S.P., Li, M., Shahveranov, A., Ye, D.W., Tian, Y.K., Interleukin-6: an emerging regulator of pathological pain. J Neuroinflammation. 2016 Jun 7;13(1):141.

52. Anitua, E., Zalduendo, M., Troya, M., Padilla, S., Orive, G., Leukocyte inclusion within a platelet rich plasma-derived fibrin scaffold stimulates a more pro-inflammatory environment and alters fibrin properties. PLoS One. 2015 Mar 30;10(3):e0121713.

53. Mariani, E., Canella, V., Berlingeri, A., Bielli, A., Cattini, L., Landini, M.P., Kon, E., Marcacci, M., Di Matteo, B., Filardo, G., Leukocyte presence does not increase microbicidal activity of Platelet-rich Plasma in vitro. BMC Microbiol. 2015 15, p. 149.

54. Mei-Dan, O., Lippi, G., Sánchez, M., Andia, I., Maffulli, N., Autologous platelet-rich plasma: a revolution in soft tissue sports injury management? Phys Sportsmed. 2010 Dec;38(4), p. 127-35.

55. Filippi, GM,, Errico, P., Santarelli, R., Bagolini, B., Manni, E., Botulinum A toxin effects on rat jaw muscle spindles. Acta Otolaryngol. 1993 May;113(3), p. 400-4. 
56. Sidebottom, A.J., Patel, A.A., Amin, J., Botulinum injection for the management of myofascial pain in the masticatory muscles. A prospective outcome study. Br J Oral Maxillofac Surg. 2013 Apr;51(3), p. 199-205.

57. Ediz, L., Çağaç, A., Delen, V., The Efficacies of Medicinal Leech Therapy and Platelet Rich Plasma Injection added to Muscle Stretching Exercises in the Treatment of Myofascial Pain Syndrome. Eastern J Med. 2021; 26(1), p. 109-116.

58. von Lindern, J.J., Niederhagen, B., Bergé, S., Appel, T., Type A botulinum toxin in the treatment of chronic facial pain associated with masticatory hyperactivity. J Oral Maxillofac Surg. 2003 Jul;61(7), p. 774-8.

59. Villa, S., Raoul, G., Machuron, F., Ferri, J., Nicot, R., Improvement in quality of life after botulinum toxin injection for temporomandibular disorder. J Stomatol Oral Maxillofac Surg. 2019 Feb;120(1), p. 2-6.

60. Kamanli, A., Kaya, A., Ardicoglu, O., Ozgocmen, S., Zengin, F.O., Bayik, Y., Comparison of lidocaine injection, botulinum toxin injection, and dry needling to trigger points in myofascial pain syndrome. Rheumatol Int. 2005 Oct;25(8), p. 604-11.

61. Meral, S.E., Tüz, H.H., Başlarlı, Ö., Evaluation of patient satisfaction after botulinum toxin A injection for the management of masticatory myofascial pain and dysfunction - A pilot study. Cranio. 2021 Jan;39(1), p. 12-16.

62. Fathy, A.I., Ali, K.M., Mostafa, A.M., Botulinum injection in the masticatory muscles for management of myofascial pain. Al-Azhar Journal of Dental Science, 2020. 23(4): p. 375-381.

63. Rohtak, P.I.O.D.S. Comparative Efficacy of PRP and Dry Needling in Management of Trigger Points in Masseter Muscle in MPS Patients. February 27, 2020; Available from: https://clinicaltrials.gov/ct2/show/record/NCT04286880.
64. Bubnov, R., Fodor, D., Latent trigger point platelet-rich plasma (PRP) injections under ultrasound-guidance for chronic myofascial pain. Journal of the Neurological Sciences, 2013. 333: p. e91.

65. Khayamzadeh, M., Ahmadi, P., Razmara, F., Safavi, K., Temporomandibular joint disorder therapy: A review. J Craniomaxillofac Res. 7(3), p. 110-125.

66. Majid, O.W., Clinical use of botulinum toxins in oral and maxillofacial surgery. Int J Oral Maxillofac Surg. 2010 Mar;39(3), p. 197-207.

67. Mor, N., Tang, C., Blitzer, A., Temporomandibular Myofacial Pain Treated with Botulinum Toxin Injection. Toxins (Basel), 2015. 7(8): p. 2791-800.

68. Bentsianov, B., Francis, A., Blitzer, A., Botulinum toxin treatment of temporomandibular disorders, masseteric hypertrophy, and cosmetic masseter reduction. Operative Techniques in Otolaryngology-Head and Neck Surgery, 2004. 15(2): p. 110-113.

69. Al-Moraissi, E.A., Alradom, J., Aladashi, O., Goddard, G., Christidis, N., Needling therapies in the management of myofascial pain of the masticatory muscles: A network meta-analysis of randomised clinical trials. J Oral Rehabil. $2020 \mathrm{Jul}$;47(7), p. 910-922.

70. Cai, Y.Z., Zhang, C., Lin, X.J., Efficacy of platelet-rich plasma in arthroscopic repair of full-thickness rotator cuff tears: a meta-analysis. J Shoulder Elbow Surg. 2015 Dec;24(12), p. 1852-9.

71. Warth, R.J., Dornan, G.J., James, E.W., Horan, M.P., Millett, P.J., Clinical and structural outcomes after arthroscopic repair of full-thickness rotator cuff tears with and without platelet-rich product supplementation: a meta-analysis and meta-regression. Arthroscopy. 2015 Feb;31(2), p. 306-20. 